\title{
A RESPONSABILIDADE SOCIAL CORPORATIVA NAS UNIVERSIDADES PÚBLICAS E PRIVADAS: O CASO DA COOPERAÇÃO ENTRE AS BIBLIOTECAS UNIVERSITÁRIAS DA CIDADE DE FREDERICO WESTPHALEN
}

\author{
Ricardo Cesar Silva \\ Bibliotecário - UFSM - Campus Frederico Westphalen - RS \\ Doutorando em Administração. \\ ricces2000@yahoo.com.br \\ Gilnei Luiz Moura \\ Doutor em Administração \\ Professor Associado - UFSM \\ mr.gmoura.ufsm@gmail.com \\ Sirlene Aparecida Santos \\ Mestre em Administração \\ Bibliotecária - UFSM \\ sirlenas2004@yahoo.com.br \\ Laércio André Gassen Balsan \\ Doutor em Administração \\ laerciobalsan@yahoo.com.br \\ Adriana Camponogara Aires Silva \\ Mestre em Letras \\ Secretária executiva UFSM - Campus de Frederico Westphalen \\ adrianaairesdasilva@hotmail.com
}

Resumo

Este artigo teve como objetivo propor a cooperação entre bibliotecas universitárias como uma forma de contribuição a Responsabilidade Social Corporativa (RSC) em relação a um olhar: social, ambiental e econômico das instituições envolvidas. Caracterizou-se como uma pesquisa qualitativa, onde foi realizado um estudo de caso entre as bibliotecas de instituições universitárias da região de Frederico Westphalen: Universidade Regional Integrada do Alto Uruguai e das Missões (URI), Universidade Federal de Santa Maria (UFSM), Instituto Federal Farroupilha (IFF) para a cooperação entre as mesmas dos materiais bibliográficos. Os procedimentos metodológicos se constituíram de três fases, primeiro foi uma coleta e pré-análise dos dados, a observação não-participante nas bibliotecas das Instituições Universitárias e aplicação do questionário semiestruturado aos bibliotecários das mesmas, depois utilizou-se da linguagem UML para o mapeamento de processos e por último o tratamento dos resultados, inferência e interpretação em consonância ao referencial teórico. Por fim, a cooperação entre as instituições mostrou-se exequível e, além disso, pode ser aproveitada para melhorar e beneficiar aspectos como: imagem da instituição, benefícios econômicos, sociais e ambientais; de acordo com as premissas da Responsabilidade Social Corporativa - RSC.

Palavras-Chave: Responsabilidade Social Corporativa (RSC); Bibliotecas Universitárias; Gestão Ambiental; Linguagem UML. 


\section{INTRODUÇÃO}

Este artigo tem como objetivo propor a cooperação entre bibliotecas universitárias como uma forma de contribuição para uma Responsabilidade Social Corporativa (RSC) em relação a um olhar: social, ambiental e econômico.

As universidades Públicas e Privadas têm como norteadoras de suas práticas: o ensino, a pesquisa e a extensão. Essa tríade segundo os autores Veiga (2012), Serrano (2012), Pryjma (2008), Severino (2007), Emmel e Krul (2017) não pode ser dissociada, uma vez que se utilizarmos somente o ensino a renovação de novos conhecimentos será prejudicada pela falta de pesquisas, ou seja, a replicação do conhecimento é relevante, entretanto, com o tempo, torna-se obsoleto pelas mudanças ambientais, tecnológicas e sociais. A extensão é uma forma de manifestação empírica dos conhecimentos adquiridos por via do ensino e da pesquisa, isto é, retorna em ações práticas o que foi aprendido no ambiente universitário (práticas jurídicas, odontológicas, empresas júnior etc). Dessa forma, devido ao retorno de suas práticas de extensão junto à sociedade, considera-se as contribuições como práticas de RSC.

As atividades das Bibliotecas Universitárias podem ser consideradas como de RSC, visto que contribuem para o contexto das Universidades no que compete à pesquisa, ao ensino e a extensão na disponibilização de conteúdo bibliográfico e digital e, além disso, coadjuvam para o desenvolvimento da comunidade acadêmica e regional. Além dessas rotinas já conhecidas na ambiência das Bibliotecas Universitárias, a parceria entre as mesmas podem gerar bons frutos para a imagem das instituições, práticas sustentáveis, econômicas e sociais, ou seja, mais um reforço para as práticas de RSC.
Dessa forma, propõe-se a cooperação entre bibliotecas universitárias como uma forma de contribuição a Responsabilidade Social Corporativa (RSC) em relação a um olhar: social, ambiental e econômico das instituições envolvidas, para que essa proposição acontecesse foi desenvolvido um modelo de empréstimo entre Bibliotecas Universitárias no qual utilizou-se a Linguagem de Modelagem Unificada (UML) como forma de mostrar graficamente a Gestão de Processos e o Mapeamento de Processos na óptica do RSC. Além da representação gráfica, o modelo se propõe a ser usado no desenvolvimento de um protótipo para que outras instituições de Ensino Superior utilizem como forma de promoção de sua imagem frente aos Stakeholders e junção ao modelo de negócios, haja vista poderá ajustar-se como prática de viés social, ambiental e econômico, além das atividades tradicionais de ensino, pesquisa e extensão.

Esta investigação baseou-se em um estudo de caso na cidade de Frederico Westphalen entre três instituições (duas públicas e uma privada): Universidade Regional Integrada do Alto Uruguai e das Missões - URI, Universidade Federal de Santa Maria - UFSM, Instituto Federal Farroupilha - IFF.

\section{REFERENCIAL TEÓRICO 2.1 AS PRINCIPAIS INICIATIVAS A RESPEITO DO CONCEITO DE RSC}

As primeiras iniciativas a respeito do RSC surgem nos Estados Unidos e, por conseguinte, na Europa até a sua chegada ao Brasil por volta dos anos 2000. O Quadro 1, mostra a evolução do conceito de RSC em relação ao tempo e, por último, perpassa pelas próprias organizações para identificar o que os gestores pensam a respeito de tal conceito.

Quadro 1 - Definições de RSC e constatação junto aos gerentes das 100 maiores empresas da Bolsa de Valores de São Paulo.

\begin{tabular}{|l|l|}
\hline Autor & Definições \\
\hline Frederick (1960, p. 60) & $\begin{array}{l}\text { “[RSC] significa que homens de negócio devem supervisionar a operação de } \\
\text { um sistema econômico cheio de expectativas do público. [...] implica uma } \\
\text { postura pública em relação aos recursos econômicos e humanos da sociedade } \\
{[\ldots] \text { vontade de ver que esses recursos são usados para grandes fins sociais e }} \\
\text { não apenas para as circunstâncias de interesses estreitos privados e das } \\
\text { empresas”. }\end{array}$ \\
\hline
\end{tabular}




\begin{tabular}{|c|c|}
\hline Friedman $(1962$, p. 120) & $\begin{array}{l}\text { "[...] usar seus recursos e dedicar-se a atividades destinadas a aumentar seus } \\
\text { lucros até onde permaneça dentro das regras do jogo, o que significa } \\
\text { participar de uma competição livre e aberta, sem enganos ou fraude" }\end{array}$ \\
\hline Davis (1973, p. 312) & $\begin{array}{l}\text { "É a consideração e resposta da empresa para questões que ultrapassam } \\
\text { exigências econômicas, técnicas e legais de realização de benefício social } \\
\text { juntamente com os ganhos tradicionais econômicos que a empresa busca". }\end{array}$ \\
\hline Carroll (1979, p. 500) & $\begin{array}{l}\text { "A responsabilidade social de uma empresa engloba as expectativas } \\
\text { econômicas, legais, éticas e filantrópicas que uma sociedade tem das } \\
\text { organizações em um determinado momento" }\end{array}$ \\
\hline McWilliams e Siegel (2001, p. 117) & $\begin{array}{l}\text { “Ações que surgem para promover algum bem social para além dos interesses } \\
\text { da empresa e daquelas exigidas por lei”. }\end{array}$ \\
\hline $\begin{array}{l}\text { Comissão das Comunidades } \\
\text { Europeias [CCE] }(2001, \text { p. } 4)\end{array}$ & $\begin{array}{l}\text { "[RSC] é, essencialmente, um conceito segundo o qual as empresas decidem, } \\
\text { numa base voluntária, contribuir para uma sociedade mais justa e para um } \\
\text { ambiente mais limpo". }\end{array}$ \\
\hline $\begin{array}{l}\text { Whetten, Rands e Godfrey (2002, p. } \\
\text { 374) }\end{array}$ & $\begin{array}{l}\text { "Expectativas sociais de comportamento corporativo [o qual] é alegado por } \\
\text { uma das partes interessadas a ser esperado pela sociedade ou moralmente } \\
\text { necessário e, portanto, justificadamente demandado por um negócio". }\end{array}$ \\
\hline $\begin{array}{l}\text { World Business Council For } \\
\text { Sustainable Development [WBCSD] } \\
(2002, \text { p. } 2)\end{array}$ & $\begin{array}{l}\text { “[RSC] é o compromisso contínuo por parte das empresas para contribuir com } \\
\text { o desenvolvimento econômico enquanto melhora a qualidade de vida dos } \\
\text { trabalhadores e seus familiares, bem como a comunidade e a sociedade em } \\
\text { geral". }\end{array}$ \\
\hline Kotler e Lee (2005, p. 3) & $\begin{array}{l}\text { "Um compromisso para melhorar o bem-estar da comunidade passa por } \\
\text { práticas discricionárias de negócios e contribuição de recursos corporativos". }\end{array}$ \\
\hline Oliveira $(2005$, p. 3) & $\begin{array}{l}\text { "[RSC] diz respeito à maneira como as empresas agem, como impactam e } \\
\text { como se relacionam com o meio ambiente e suas partes legitimamente } \\
\text { interessadas (os chamados 'stakeholders', ou seja, empregados, fornecedores, } \\
\text { governo e sociedade em geral)". }\end{array}$ \\
\hline $\begin{array}{l}\text { Global Reporting Iniciative [GRI] } \\
(2012, \text { p. 10) }\end{array}$ & $\begin{array}{l}\text { “[RSC é] uma 'licença social de operação' da sociedade [...], a capacidade de } \\
\text { uma organização para falar de aspectos econômicos, ambientais e sociais de } \\
\text { suas operações de um modo confiável e coerente tem um valor muito alto } \\
\text { hoje em dia." }\end{array}$ \\
\hline Instituto Ethos (2012) & $\begin{array}{l}\text { "[RSC] é a forma de gestão que se define pela relação ética e transparente da } \\
\text { empresa com todos os públicos com os quais ela se relaciona e pelo } \\
\text { estabelecimento de metas empresariais que impulsionam o desenvolvimento } \\
\text { sustentável da sociedade, preservando recursos ambientais e culturais para as } \\
\text { gerações futuras, respeitando a diversidade e promovendo a redução das } \\
\text { desigualdades sociais". }\end{array}$ \\
\hline $\begin{array}{l}\text { Irigaray, Vergara e Araújo (2017, p. } \\
\text { 85) }\end{array}$ & $\begin{array}{l}\text { “[...] apenas um quarto das empresas [100 maiores empresas do Ibovespa] da } \\
\text { amostra entende RSC de forma ampla e se demonstram engajadas com } \\
\text { amplitude alta das práticas com essas ações, quando o conceito de } \\
\text { responsabilidade social envolve os valores da empresa, questões de legado, } \\
\text { sustentabilidade, mitigação de riscos, redução de impactos, compromissos } \\
\text { éticos e pactuados, desenvolvimentos das comunidades locais, projetos de } \\
\text { recuperação ambiental e preservação." }\end{array}$ \\
\hline
\end{tabular}

Fonte: Adaptado de Irigaray, Vergara e Araújo (2017). 
No Quadro 1, até meados do final de década de 60, observa-se a visão que as empresas devem prestar contas a um único público: os acionistas. Dessa forma, de acordo com a menção de Friedman (p. 120, 1962) "[...] usar seus recursos e dedicar-se a atividades destinadas a aumentar seus lucros até onde permaneça dentro das regras do jogo" enquanto a empresa estiver lucrando e não utilizando de práticas ilícitas no mercado a sua prioridade são os investidores.

No final da década de 70, as empresas percebem a importância de retribuir e diminuir o impacto de suas práticas na sociedade, como pode ser observado no excerto de Carroll (1979, p. 500) "A responsabilidade social de uma empresa engloba as expectativas econômicas, legais, éticas e filantrópicas que uma sociedade tem das organizações em um determinado momento". Entretanto, até meados dos anos 2000, as empresas não sabiam como tirar proveito de suas práticas de RSC e, assim, não atrelaram o conceito ao modelo de negócio.

A partir dos anos 2000, as empresas atentaram que poderiam beneficiar-se das práticas sociais e acrescenta-se uma maior preocupação com o meio ambiente conforme mencionado por GRI (2012, p. 10) "[RSC é] uma 'licença social de operação' da sociedade [...], a capacidade de uma organização para falar de aspectos econômicos, ambientais e sociais de suas operações de um modo confiável e coerente tem um valor muito alto hoje em dia." Constata-se uma preocupação com a sociedade, aspectos econômicos ligados a imagem da organização, bem como, o impacto gerado ao meio ambiente.

Irigaray, Vergara e Araújo (2017, p. 85) resgataram os principais aspectos do RSC: "[...] sustentabilidade, mitigação de riscos, redução de impactos, compromissos éticos e pactuados, desenvolvimentos das comunidades locais, projetos de recuperação ambiental e preservação". e, além disso, agregaram a visão dos gestores das organizações a respeito do que eles entendem das práticas ligadas ao RSC e constatou-se que apenas um quarto das empresas nacionais ligadas ao Índice da Bolsa de Valores de São Paulo - Ibovespa (100 maiores) entendem os princípios lato sensu.

Destarte, o percurso do RSC deu-se, a priori, com a visão reducionista das empresas em obter retorno financeiro, somente, aos acionistas; em seguida, as organizações perceberam as cobranças da sociedade e iniciaram os primeiros trabalhos voltados às práticas sociais sem a necessidade de retorno financeiro e promoção da imagem da organização; por conseguinte, atrelou-se o RSC ao modelo de negócios, bem como, uma maior preocupação com as questões ambientais e, por último, Irigaray, Vergara e Araújo (2017) nas suas investigações resgatam a visão dos gestores das organizações listadas no Ibovespa (100 maiores) em relação ao RSC.

\subsection{BIBLIOTECAS UNIVERSITÁRIAS}

As Bibliotecas Universitárias estão no bojo das atividades-fim das instituições de ensino superior, citadas por Low (2004, p.11) como de " $[\ldots]$ ensino-aprendizagem, compreendendo, entre outras, acesso a informação e conhecimento, espaços virtuais de aprendizagem e meios de comunicação". Resumindo, as instituições desenvolvem atividades relativas à docência, ao serviço de biblioteca, ao uso da tecnologia da informação e à comunicação.

As Bibliotecas Universitárias têm função de destaque no quadro dos setores das instituições de ensino superior, visto que as subsidiam com produtos e serviços informacionais. Além disso, salvaguardam os materiais bibliográficos e digitais das organizações para fins de pesquisa, ensino e extensão.

O principal norte da Biblioteca Universitária é a Gestão da Informação, que, para Dias e Belluzzo (2003), consiste em um conjunto de conceitos, princípios, métodos e técnicas, os quais são utilizados na prática administrativa que visa o serviço de informação para atingir a missão e os objetivos desejados. De acordo com Choo (2003), pode ser compreendida como a gestão de uma rede de processos: adquire, cria, organiza, distribui e usa a informação.

\subsubsection{Gestão de processos}

A Gestão de Processos, no sentido estritamente empresarial, caracteriza-se como os incrementos e as transformações que os produtos e serviços passam desde a sua entrada "inputs" até a sua saída "outputs" da empresa. Os processos, de acordo com Davenport (1994), constituem uma sincronização de 
atividades de trabalho com tempo - começo, meio e fim - e espaço definidos.

Em vista disso, a Gestão de Processos obstina-se à redução do retrabalho, à economia de recursos materiais e humanos, à eficiência do trabalho e à busca pela qualidade de produtos e serviços. Para Davenport (1994, p. 8), processos são “(...) a estrutura pela qual uma organização faz o necessário para produzir valor para os seus clientes".

$\mathrm{Na}$ ambiência pública e privada, existem diversas instâncias dentro da mesma instituição. Dessa forma, há várias modalidades de processos com objetivos distintos, conforme a seguir:

1. Processos de Negócios: estão voltados para o atendimento das demandas dos clientes externos, no que compete a produtos e serviços de qualidade, e visam atingir os objetivos organizacionais;

2. Processos Organizacionais: são inerentes ao funcionamento coordenado dos subsistemas internos e vislumbram dar sustentabilidade aos processos de negócios; e

3. Processos Gerenciais: têm como objeto as pessoas que decidem dentro da instituição (gerentes, diretores, presidente) e como alvo o ajuste dos procedimentos internos na direção da missão institucional (Gonçalves, 2000).

\subsubsection{Mapeamento de processos}

As empresas são compostas de processos que monitoram e geram agregação de valor a seus produtos e serviços. De acordo com Davenport (2013), os processos são construídos por pessoas, por meio de seus conhecimentos aplicados. Assim, para descobrir os tipos de processos (de negócios, organizacionais ou gerenciais) existentes em uma empresa e identificar possíveis falhas ou otimizá-los, é necessário fazer o seu mapeamento por meio de alguma ferramenta analítica.

Em vista disso, existem várias ferramentas usadas para o Mapeamento de Processos. Uma delas é a linguagem unificada UML, que é uma linguagem visual voltada para orientação a objetos (modelo de análise baseado na interação entre as unidades do software). Seu uso possibilita o acompanhamento do processo de negócio ao longo do tempo e foi desenvolvida para o levantamento dos requisitos de processos de negócios no desenvolvimento de softwares. Para a utilização correta da linguagem UML, deve-se fazer o levantamento dos requisitos existentes nos processos de negócios considerados e posteriormente estruturar graficamente criando um modelo completo de análise primando sempre pela visualização, especificação, construção e documentação.

O modelo de análise UML do diagrama de Casos de Uso (visão global dos processos) apresenta os atores envolvidos, a interação dos atores em relação a outros atores e os atores e seus processos e o diagrama de Atividades serve para mostrar, em raias, o processo que cada ator deve desempenhar bem como o encadeamento das atividades - o que deve ser feito em etapas pormenorizadas, indicando o início das atividades até o seu término - e, também, representa as atividades que podem ser realizadas simultaneamente.

Foi definido um manual de procedimentos que contém a documentação dos passos, processos, atividades, atores e interações visto que o modelo apresentado na ferramenta UML cita apenas os elementos sem a descrição pormenorizada das atividades.

\section{PERCURSO METODOLÓGICO}

No rol das pesquisas qualitativas, esta investigação enquadra-se como Estudo de Caso, o qual, conforme Yin (2005), objetiva esclarecer as indagações do tipo "como" e "qual", tem caráter explanatório e se orienta para a dependência das incidências - quatro instituições de ensino superior que se situam em Frederico Westphalen (UFSM, IFF e URI) -, ao contrário dos Casos Múltiplos, cujos nortes são o viés independente das incidências. A escolha do método de Estudo de Caso justifica-se, também, pelo fato de abordar questões operacionais e contemporâneas.

Em vista disso, Godoy (1995, p. 25) observa que, dentro da pesquisa Qualitativa, existem várias ramificações, posto que $\mathrm{o}$ Estudo de Caso "[...] caracteriza como um tipo de pesquisa cujo objeto é uma unidade que se analisa profundamente". Ainda segundo a autora, "Tem por objetivo proporcionar vivência da realidade por meio da discussão, análise e tentativa de solução de um problema extraído da vida real". No que se refere ao desenvolvimento da pesquisa, deve ser feita tendo em vista o problema ou questão que preocupa o investigador (Godoy, 1995). 
Uma das subdivisões do Estudo de Caso é a pesquisa Exploratória, que, conforme Gil (2010), caracteriza-se por proporcionar familiaridade com o problema, a construção e a elucidação de hipóteses, e tem como peculiaridade o planejamento flexível, pois conecta os mais variados aspectos, fatos ou fenômenos relacionados à pesquisa. A coleta de dados pode ser realizada por meio de levantamento bibliográfico, questionários semiestruturados realizados com pessoas ou grupos-chave (stakeholders) e vivência de experiências práticas. Os estudos exploratórios, em virtude da flexibilidade, enquadram os tipos de investigação estudo de caso, levantamento bibliográfico e de campo.

Os procedimentos metodológicos se constituíram de três fases: 1) coleta e préanálise dos dados, 2) utilização da linguagem UML para o mapeamento de processos e 3) tratamento dos resultados, inferência e interpretação em consonância ao referencial teórico.

$\mathrm{Na}$ primeira fase, constituiu-se do levantamento das informações junto às instituições parceiras, por meio da observação não participante e questionário semiestruturado, que se caracterizou pela visita in loco realizada no mês de Dezembro de 2016 nos dias: 04 e 05 no IFF/FW, 06 e 07 na URI/FW e 08 e 09 na UFSM/FW, para constatar se as instituições realizavam ou não empréstimos domiciliares, quais eram os seus prazos de devolução e, no caso de atraso, como ocorria o pagamento da multa. Os questionários semiestruturados foram enviados para bibliotecários via correio eletrônico para a manifestação do que fora necessário para a realização da parceria entre as três instituições universitárias e, porventura, suas ideias estão discriminadas na Figura 6.

$\mathrm{Na}$ segunda fase, utilizou-se a linguagem UML para mapear as informações e dispor no formato de diagramas de Casos de Uso e de Atividades e, assim, foi possível observar os processos inerentes a cada biblioteca na Figura 1.

$\mathrm{Na}$ terceira fase, procurou-se alinhar o referencial teórico do RSC, Bibliotecas Universitárias, Gestão de Processos e Mapeamento de Processos em associação ao modelo de empréstimo entre Bibliotecas Universitárias para se obter vantagem competitiva em relação aos concorrentes, melhorar a imagem das instituições e beneficiar a comunidade acadêmica em relação a ter mais possibilidades de encontrar o material bibliográfico desejado.

\section{RESULTADOS}

Com base nas informações e fragmentos dos discursos coletados, foram identificados os mapeamentos que estão dispostos a seguir. Nessa seção, serão tratados os assuntos referentes aos diagramas de Casos de Usos, bem como de suas especificações para posterior aplicação.

A representação gráfica do Caso de Uso empréstimo entre bibliotecas pode ser observado na Figura 1. 
Figura 1 - Caso de Uso - empréstimo entre bibliotecas (visão geral).

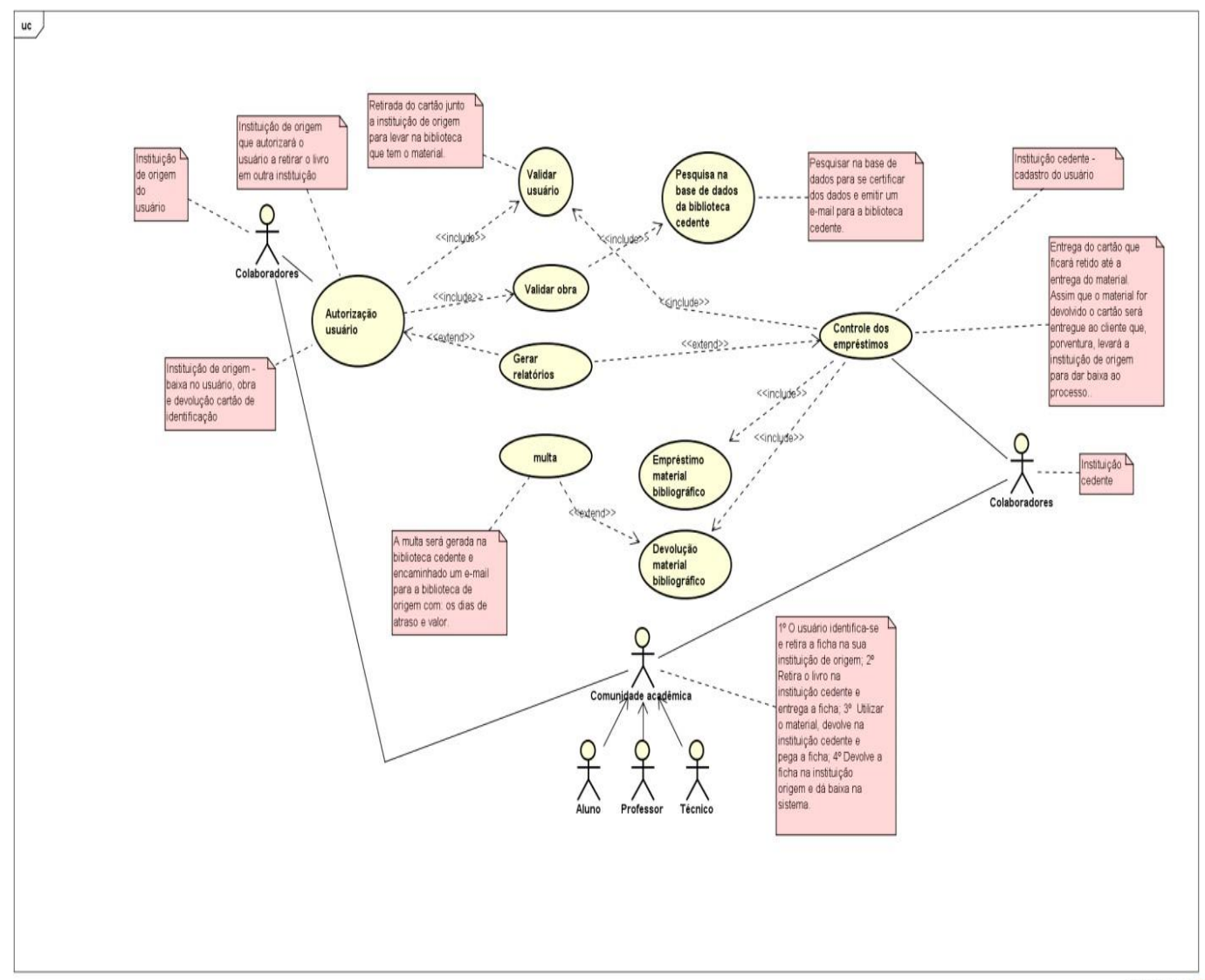

Fonte: Elaborado pelos autores

A seguir, são descritos os passos e os Digramas de Atividades que balizam as relações entre as universidades. a) Definição do acordo de parceria e ressarcimento entre as instituições:

Na Figura 2, observa-se a relação entre as universidades para o ressarcimento quando houver perda de material ou dano.

Figura 2 - Atividade: Ressarcimento entre as instituições.

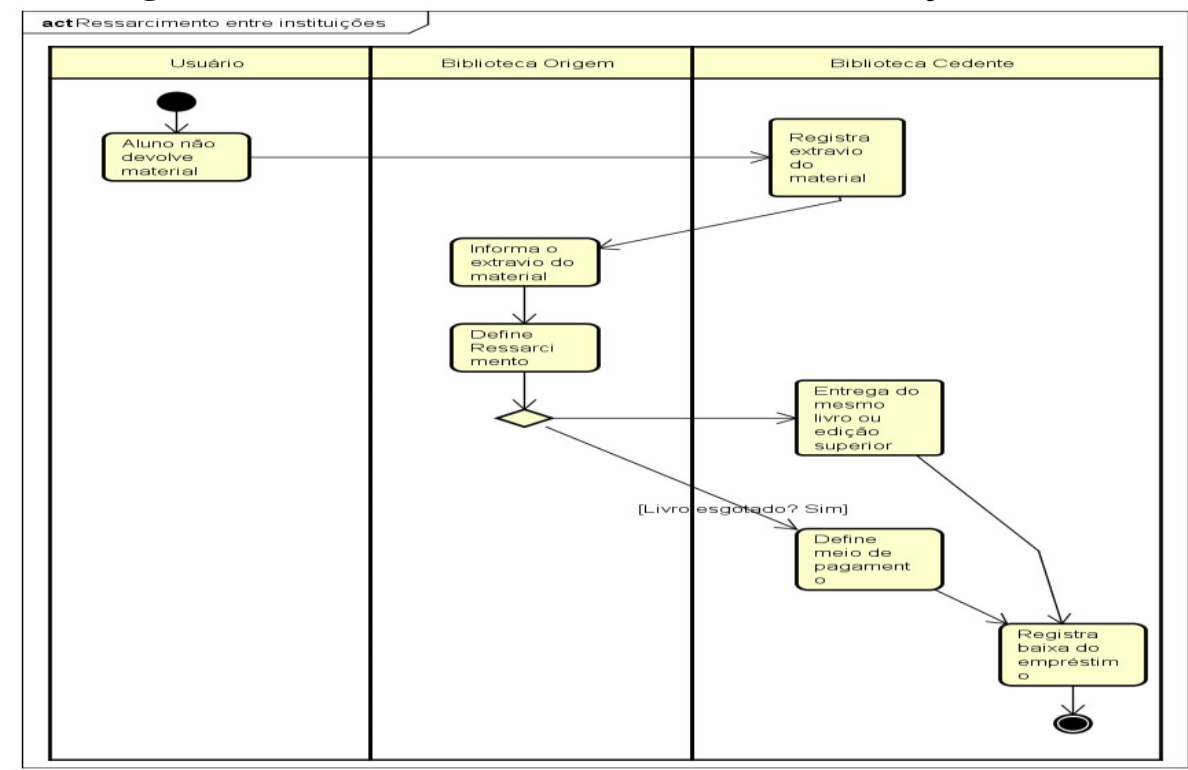

Fonte: Elaborado pelos autores. 
Essa atividade só é utilizada, caso o usuário, por algum motivo, não devolva o livro e não ressarça a instituição cedente. Dessa forma, fica com pendência na instituição de origem, pois esta entrará em contato com a instituição cedente e devolverá o livro de mesma edição ou superior e, caso o livro esteja esgotado, pagará o valor do livro em espécie.

$\mathrm{Na}$ próxima subseção, é convencionado como será a solicitação do serviço, bem como a reserva na instituição cedente. a) Solicitação do serviço de empréstimo entre as bibliotecas:

Na Figura 3, observa-se o passo a passo referente às atividades e processos que cada ator deve trilhar para a consecução do serviço de empréstimo entre as bibliotecas das instituições parceiras, ou melhor, são descritas as etapas do processo de reserva do material em relação à biblioteca que dispõe do acervo.

Figura 3 - Atividade: solicitação de reserva do material.

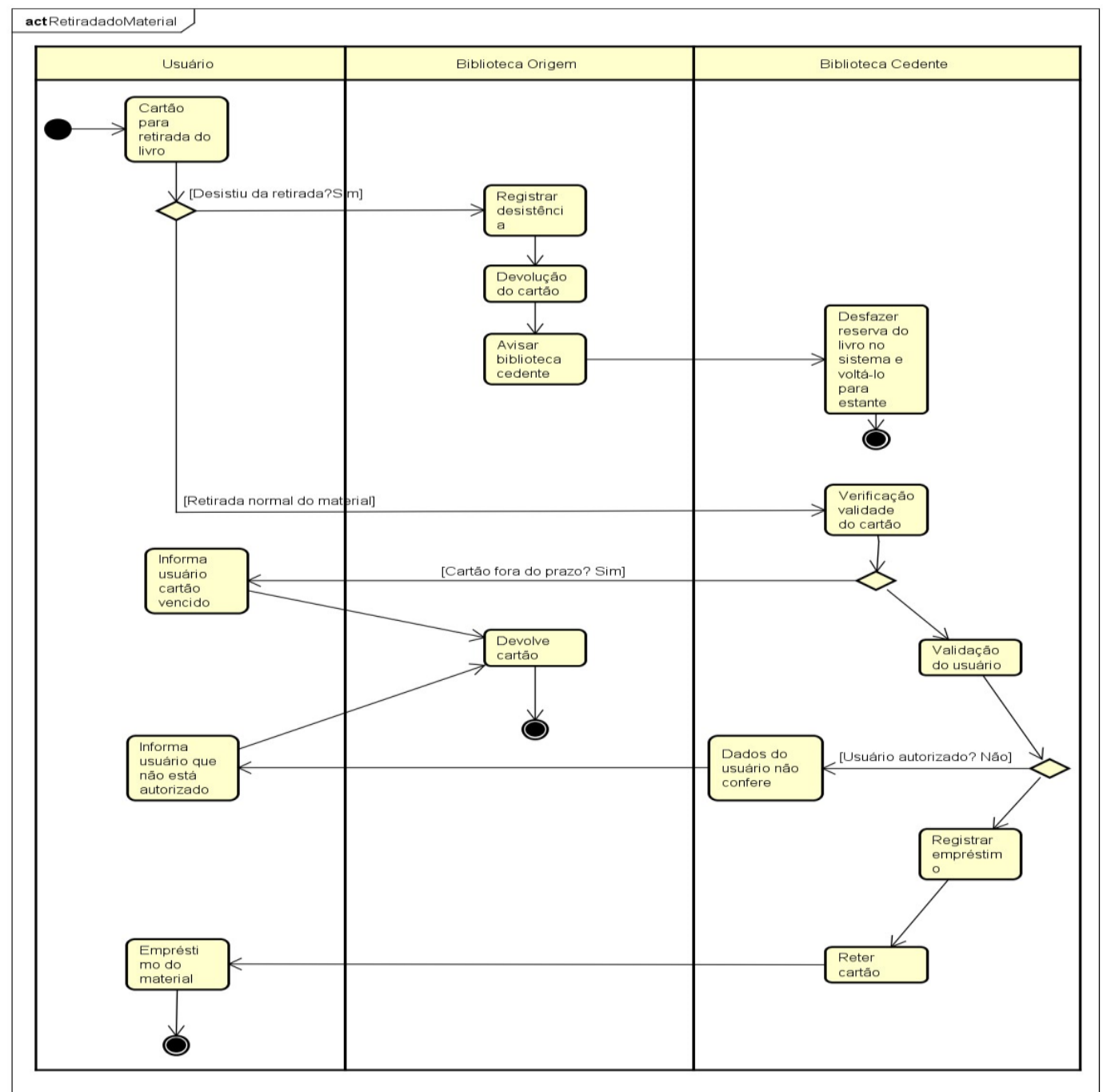

Fonte: Elaborado pelos autores.

1. O usuário solicita o livro à instituição de origem;

2. A biblioteca de origem realiza a validação do usuário;

a. O usuário possui alguma pendência na biblioteca de origem: multa, extravio do material, não pertence à instituição ou está com a carteirinha de outro usuário;

3. Cada instituição tem direito a retirar 5 livros em outra. Nesse caso, no momento da escolha da instituição, após a pesquisa na base de dados e se o livro estiver presente somente naquela instituição, a biblioteca de origem 
informa ao usuário que ele deve aguardar a chegada de um cartão;

4. Após a certificação de que o usuário não possui pendência e estando o cartão à disposição do usuário, pode ser iniciado o processo de empréstimo;

a. Registro dos dados do usuário: data inicial e final do empréstimo, nome do usuário e matrícula;

b. Registro dos dados do material bibliográfico: título da obra, autor e dados de registro interno da obra;

c. Comunicação ao usuário sobre a posse do material por 6 dias consecutivos, a contar da data da retirada;

d. Comunicação ao usuário que ele tem 3 dias úteis para retirar o material na biblioteca cedente e um alerta sobre o zelo com o material, pois, caso ocorra algum dano, o ressarcimento é imediato;

5. Entrega ao usuário do cartão de identificação, junto com um formulário que deve ser preenchido com informações relativas ao feedback do serviço prestado, o qual dará direito à retirada de 1 livro;

6. A biblioteca de origem informa à biblioteca cedente os dados do material bibliográfico solicitado - dia da solicitação, título da obra e autor -, bem como os dados de quem irá retirar o material - nome, matrícula;

7. A biblioteca de origem comunica o usuário que deve comparecer à biblioteca cedente com o documento de identificação.

8. A próxima subseção apresenta os aspectos relacionados à retirada do material na instituição cedente.

b) Retirada do material na instituição cedente:

Na Figura 4, menciona-se o trâmite da realização do empréstimo, ou melhor, como o usuário deve proceder para a retirada do material na biblioteca da instituição cedente.

Figura 4 - Atividade: Retirada do material na biblioteca da instituição cedente

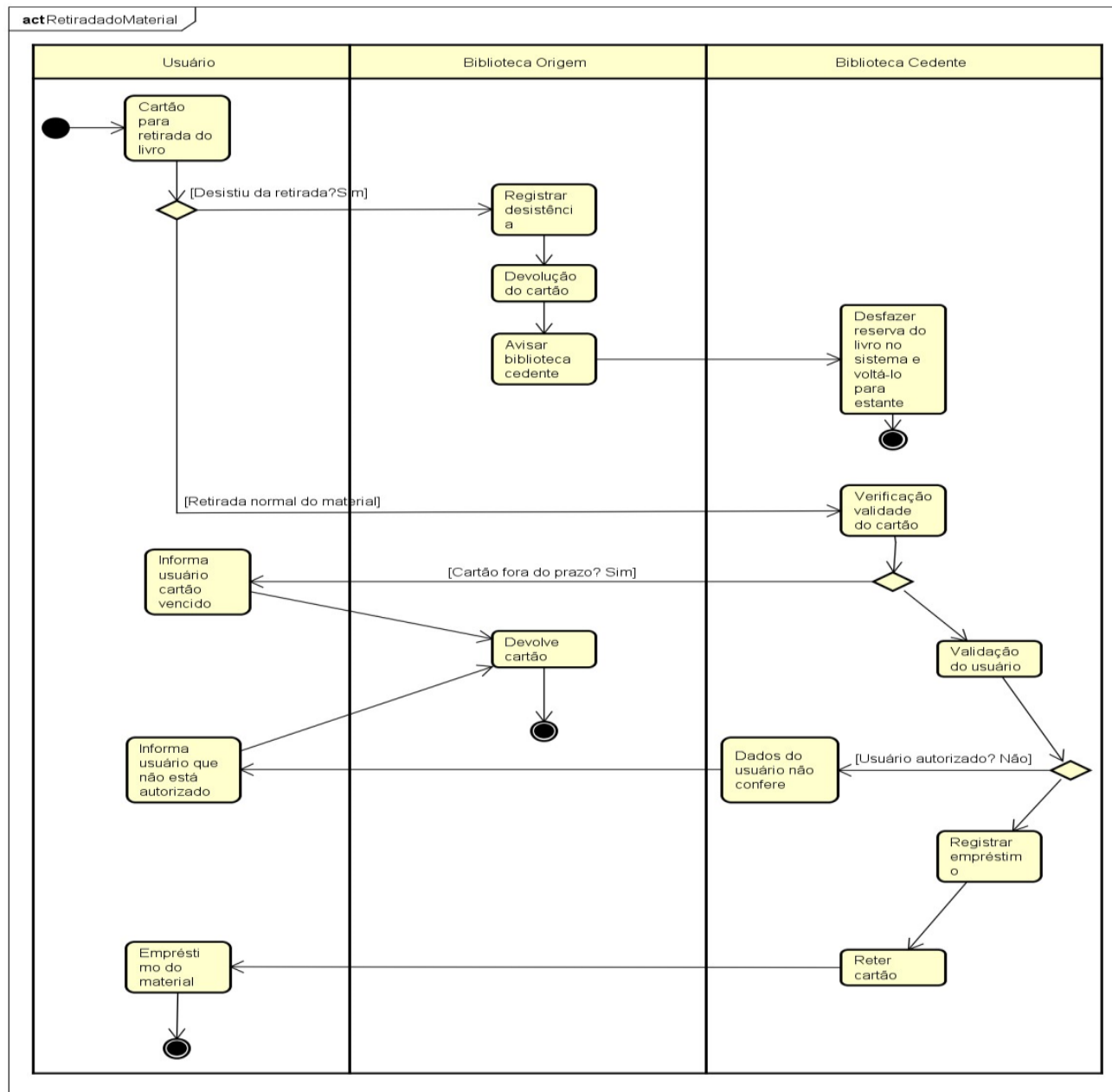

Fonte: Elaborado pelos autores. 
1. O usuário, de posse do cartão, pode desistir da retirada do livro, porém deve entregá-lo à instituição de origem, que dará baixa no empréstimo e avisará a biblioteca cedente da desistência. Assim, o material bibliográfico retorna à estante e será ativado, no sistema interno da biblioteca, para posterior empréstimo;

2. O usuário deve se apresentar na biblioteca cedente no prazo de 3 dias úteis. Se não fizer isto, deve iniciar nova solicitação de empréstimo junto à instituição de origem;

3. A biblioteca cedente verifica a identificação do usuário, se é compatível com os dados mencionados no $e$-mail. Para isso, ele deve apresentar o cartão de identificação, em conjunto com a carteirinha de identificação da instituição de origem ou documento com foto;
4. A biblioteca cedente registra o empréstimo, informa ao usuário - data inicial e final do empréstimo, título e nome do autor - e retém o cartão até a devolução do material.

5. A biblioteca cedente entrega o material e solicita a ficha de feedback obtida na instituição de origem.

A próxima subseção trata do processo de devolução do material bibliográfico à instituição cedente, bem como da cobrança de multa ao usuário quando incorrer em atraso ou dano ao material emprestado.

d) Devolução do material à biblioteca cedente:

A Figura 5 apresenta as etapas a serem cumpridas pelo usuário para efetuar a devolução do material emprestado pela biblioteca cedente e explica como se dará a cobrança de multa em caso de atraso ou extravio do material.

Figura 5 - Atividade: Devolução do material à instituição da biblioteca cedente.

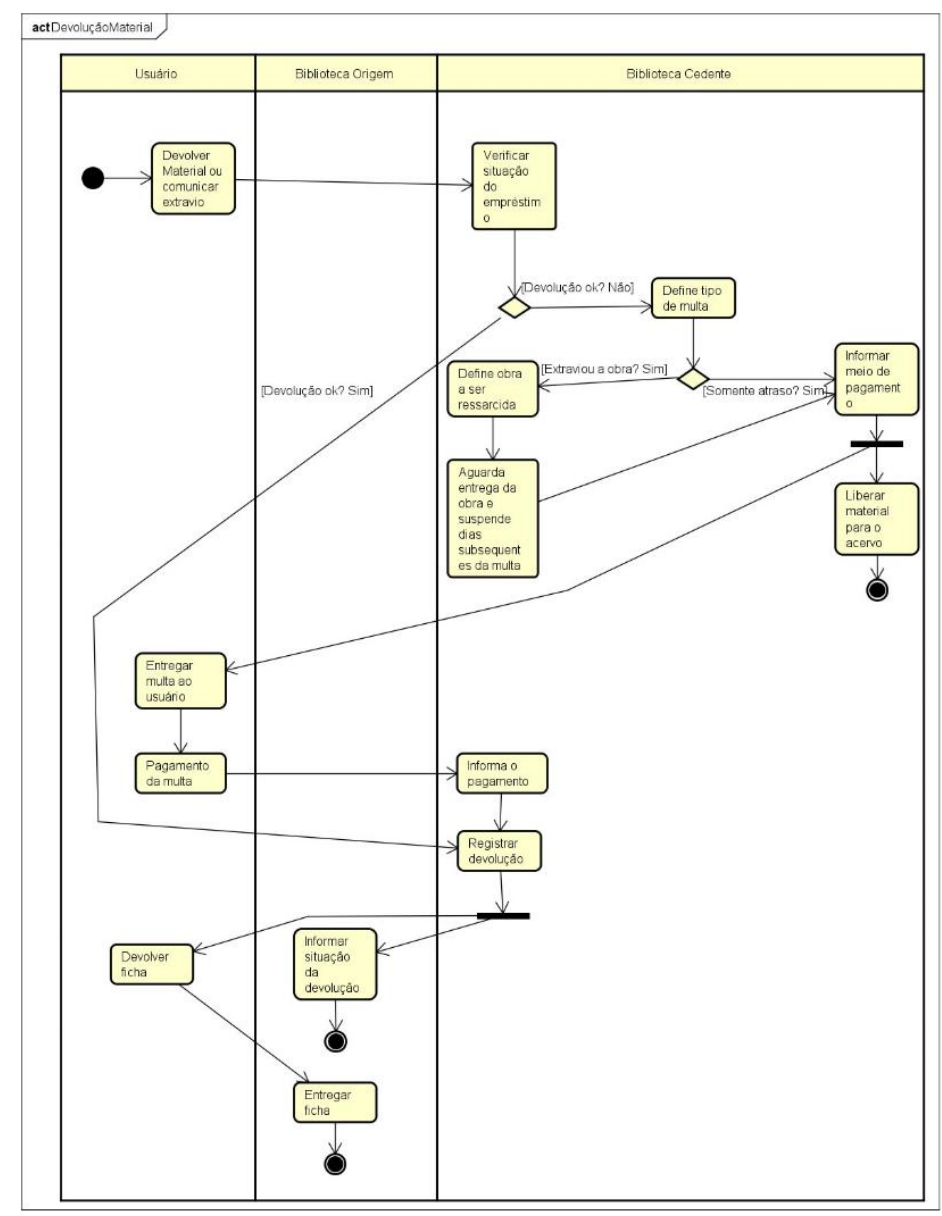

Fonte: Elaborado pelos autores. 
1. Cabe ao usuário devolver o material bibliográfico à biblioteca cedente no mesmo estado físico em que o retirou.

2. O usuário devolve o material em estado irregular ou fora do prazo de entrega:

- O atendente avalia o material, o qual, caso esteja danificado, deverá ser substituído por edição igual ou superior e, se estiver esgotado, por outro material indicado pelo bibliotecário;

- O usuário deve ressarcir a biblioteca pelos dias de atraso, conforme a norma do local de onde o material bibliográfico foi retirado;

- O cartão fica retido até a regularização da situação de empréstimo do material bibliográfico;

3. O usuário devolve o material em estado regular e no prazo de entrega:

- $\mathrm{O}$ atendente registra os dados da entrega do material e emite uma mensagem, por e-mail ou telefone, à biblioteca de origem, avisando que a entrega foi realizada com sucesso;

- O usuário recebe o cartão de empréstimo e o devolve à biblioteca de origem, para que o próximo cliente tenha acesso ao serviço;
- $\mathrm{O}$ atendente da biblioteca de origem registra o fim do empréstimo e disponibiliza o cartão ao próximo usuário.

A próxima subseção trata os aspectos relacionados aos indicadores de satisfação do serviço, que servem de medida para verificar se os usuários estão satisfeitos ou não com os serviços prestados entre as instituições parceiras. Dessa forma, é possível fazer ajustes para a melhora da prestação do serviço.

\section{CONSIDERAÇÕES FINAIS}

As organizações, sejam elas públicas ou privadas, almejam, em um primeiro momento, atender às necessidades de seus clientes/usuários e, por conseguinte, criar uma esfera positiva de confiança e superação em relação à qualidade no que compete a seus produtos e serviços em detrimento dos ofertados pela concorrência. Uma das formas de uma organização agregar valor aos seus produtos/serviços é por meio das parcerias, que visa apresentar benefícios mútuos às instituições participantes, sem onerar nenhuma das partes. Pode observar na Figura 6, como as instituições podem beneficiar-se do modelo de parceria e, possivelmente, atingir o patamar do RSC.

Figura 6 - Benefícios da parceria entre as Bibliotecas Universitárias em consonância ao RSC.

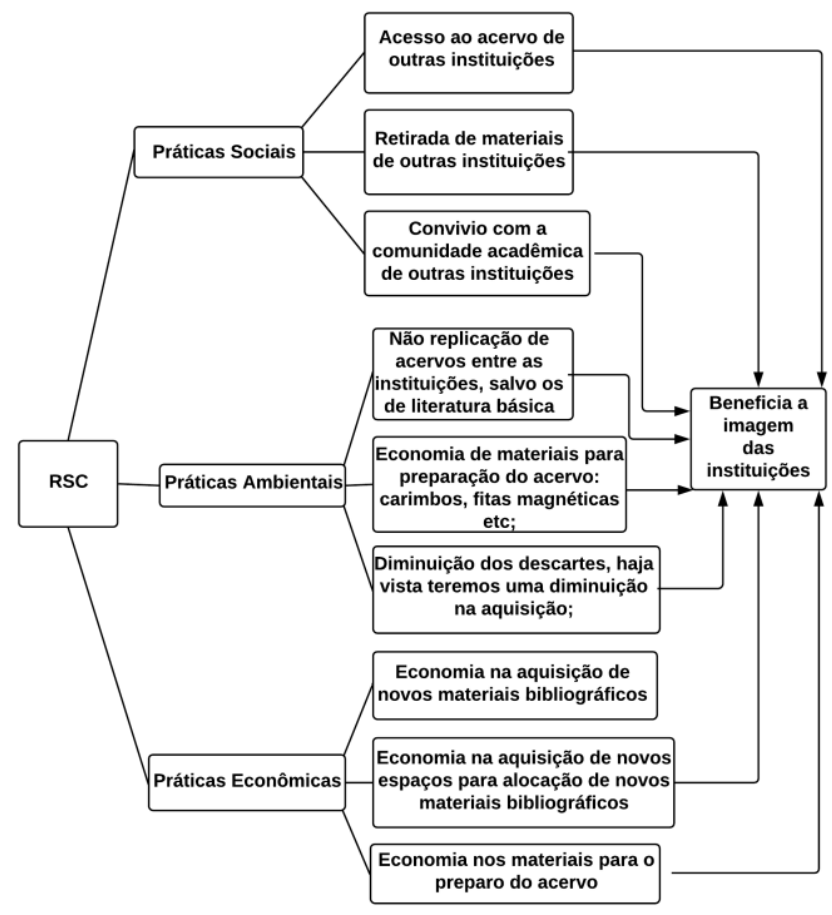

Fonte: Elaborado pelos autores. 
O resultado dessa parceria traz benefícios mútuos aos integrantes por meio do viés do RSC que segundo Global Reporting Iniciative (2012, p. 10) "licença social de operação da sociedade [...], a capacidade de uma organização para falar de aspectos econômicos, ambientais e sociais de suas operações de um modo confiável e coerente tem um valor muito alto hoje em dia." Dessa forma, em relação aos aspectos econômicos: as instituições podem realizar parcimônia nos gastos comprando materiais bibliográficos que não contenham na rede $\mathrm{e}$, somente, os exigidos pelas avaliações do Ministério da Educação MEC; ambientais: uso racional da compra, ou seja, menor impacto ambiental na não recompra de materiais pertencentes à rede, bem como, economia nos materiais que geram degradação ambiental para preparação do acervo: carimbos, fitas magnéticas, etiquetas, folhas de sulfite etc.; sociais: a comunidade acadêmica terá acesso a um vasto material bibliográfico, além de conhecer o acervo de outras instituições. As instituições universitárias, podem, além dos aspectos mencionados, promover a sua imagem como uma instituição parceira que procura trabalhar em conjunto a outras instituições de ensino da região.
Observou-se que o modelo de parceria pode ser replicado para outras cidades de portes pequeno e médio, exceto para as de porte grande. Em cidades maiores, devido à extensão territorial, acrescida dos problemas de mobilidade urbana, dificultam a retirada do material bibliográfico pelo usuário/cliente - o qual participa de todas as etapas do processo, desde a retirada à devolução do material à instituição cedente - e o controle do processo pelas instituições.

Outro complicador são os vários tipos e portes das instituições que podem participar da parceria: pública, privada, comunitária, $\mathrm{ONG}$ 's etc.

Esta investigação limitou-se aos materiais bibliográficos, e, como proposta para trabalhos futuros, os meios digitais e as bases de dados poderiam ser organizados de forma a compartilhar recursos. Um acordo de parceria entre as instituições com os distribuidores dessas bases podem gerar bons frutos: redução de custos operacionais e oferta de mais informações e conhecimentos aos players envolvidos. Outra limitação desse trabalho refere-se a visão não integrada a outros setores das Instituições que pode ser tratada como proposta na continuação deste trabalho.

\title{
CORPORATE SOCIAL RESPONSIBILITY IN PUBLIC AND PRIVATE UNIVERSITIES: THE CASE OF COOPERATION AMONG THE UNIVERSITY LIBRARIES OF THE CITY OF FREDERICO WESTPHALEN.
}

\begin{abstract}
This article aimed to propose cooperation between university libraries as a way of contributing to Corporate Social Responsibility (CSR) in relation to a social, environmental and economic view of the institutions involved. It was characterized as a qualitative research, where a case study was carried out between the libraries of university institutions of the region of Frederico Westphalen: Integrated Regional University of Alto Uruguay and the Missions - URI, Federal University of Santa Maria - UFSM, Farroupilha Federal Institute - IFF for the co-operation between them of bibliographic materials. The methodological procedures consisted of three phases, first was a collection and pre-analysis of the data to non-participant observation in the libraries of the University Institutions and application of semi-structured questionnaire to librarians thereof after USER or from the UML for mapping of processes, and finally the treatment of results, inference and interpretation in line with the theoretical framework. Finally, cooperation between institutions has proved feasible and can be used to improve and benefit aspects such as: image of the institution, economic, social and environmental benefits; according to the premises of Corporate Social Responsibility - CSR.
\end{abstract}

Keywords: CSR; University Libraries; Environmental Management; UML. 


\section{REFERÊNCIAS}

CARROLL, A.B. Three-dimensional conceptual model of corporate performance.

Academy of Management Review, v.4, n.4, p. 497-505, 1979.

CHOO, C.W. A organização do conhecimento: como as organizações usam a informação para criar significado, construir conhecimento e tomar decisões. São Paulo: Senac, 2003.

\section{COMISSÃO DAS COMUNIDADES}

EUROPEIAS. Livro verde: promover um quadro europeu para a responsabilidade social das empresas. Bruxelas, 2001.

COSTA, J. S. Docência no Ensino Superior: professor aulista ou professor pesquisador? Caderno Discente do Instituto Superior de Educação, v.2 n. 2, p. 41-61, 2008.

\section{DAVENPORT, T. H. Reengenharia de}

Processos: como inovar na empresa através da tecnologia da informação. Rio de Janeiro; Campus, 1994.

DAVENPORT, T. H. Gestão de Processos no Trabalho do Conhecimento. In: J. V. ROSEMANN (Org.). Manual de BPM: Gestão de processos de negócio. Porto Alegre: Bookman, 2013. p. 17-36.

DAVIS, K. The case for and against business assumption of social responsibilities. The Academy of Management Journal, v.16, n.2, p. 312-322, 1973

DIAS, M. M. K.; BELUZZO, R. C. B. Gestão da informação em ciência e tecnologia sob a ótica do cliente. São Paulo: Edusc, 2003.

EMMEL, R.; KRUL, A. J. A docência no ensino superior: reflexões e perspectivas.

Revista Brasileira de Ensino Superior, v.3, n. 1, p. 42-55, 2017.

FREDERICK, W. The growing concern over business responsibility. California

Management Review, v. 2, p. 54-61, 1960.

FRIEDMAN, M. Capitalismo e liberdade. 3. ed. São Paulo: Nova Cultura, 1962.
GLOBAL REPORTING INICIATIVE.

Relatórios de sustentabilidade da GRI: quanto vale essa jornada? 2012.

GIL, A. C. Como elaborar projetos de pesquisa. 5. ed. São Paulo: Atlas, 2010.

GODOY, A. S. Pesquisa qualitativa: tipos fundamentais. Revista de Administração de Empresas, São Paulo, v. 35, n. 3, p. 20-293, 1995.

GONÇALVES, J. E. L. As empresas são grandes coleções de processos. Revista de Administração - RAE, v.40, n.1, p. 6-19, 2000.

INSTITUTO ETHOS. Instituto Ethos de Empresas e Responsabilidade Social, 2017.

IRIGARAY, H. A. R., VERGARA, S. C. ARAÚJO, R. G. Responsabilidade Social Corporativa: o que revelam os Relatórios Sociais das Empresas. Organizações \& Sociedade, v. 24, n. 80, p. 73-

LOW, T. A percepção sobre o valor da utilização de recursos de TI para a atividade-fim em uma instituição de ensino superior. Dissertação (Mestrado) -

Universidade Federal do Rio Grande do Sul, 2004.

MCWILLIAMS, A.; SIEGEL, D. Corporate social responsibility: a theory of the firm perspective. Academy of Management Review, v. 26, n.1, p. 117-27, 2011.

OLIVEIRA, J. Uma avaliação dos balanços sociais das 500 maiores [versão eletrônica]. RAE Eletrônica, v. 4, n.1, p. 1-19.

PRYJMA, M. F. O professor do ensino superior e a pesquisa. - Nuevas Regulaciones em América Latina, Buenos Aires, Argentina, 2008, Buenos Aires, Argentina, 7. Anais do Seminário Redestrado

SERRANO, R. M. S. M. Conceitos de extensão universitária: um diálogo com Paulo Freire [versão eletrônica], Grupo de Pesquisa em Extensão Popular, v. 13, n. 8, p. 1-15, 2013.

SEVERINO, A. J. Metodologia do trabalho científico. 23. ed. São Paulo: Cortez, 2007. 
VEIGA, I. P. A. Docência universitária na educação superior. In: SIMPÓSIO DOCỂNCIA NA EDUCAÇÃO SUPERIOR, 6., Brasília, 2006. Anais... Brasília: Instituto de Estudos e Pesquisas Educacionais "Anísio Teixeira" (INEP), 2006.

WHETTEN, D., RANDS, G., \& GODFREY, P. What are the responsibilities of business to society? In: A. Pettigrew, H. Thomas \& R. Whittington (Eds.). Handbook of strategy and management. London: Sage, 2002. p. 373-408.

WORD BUSINESS COUNCIL FOR SUSTAINABLE DEVELOPMENT. CSR: meeting changing expectations. Geneva, France, 2002. (Relatório de Pesquisa).

YIN, R. K. Estudo de caso: planejamento e métodos. 3. ed. Porto Alegre: Bookman, 2005. 